\title{
Treinamento de pais em grupo: um relato de experiência
}

\section{Parental training in group: an experience report}

\author{
Marilia Velasco COELHO \\ Sheila Giardini MURTA
}

\section{Resumo}

Este artigo descreve uma experiência de treinamento de pais e os efeitos encontrados sobre o desenvolvimento de práticas educativas parentais positivas, habilidades sociais educativas, e enfrentamento a estressores externos. Cinco mães e dois pais participaram de uma intervenção grupal, com 20 sessões de 90 minutos e periodicidade semanal. Foram utilizadas técnicas comportamentais, como modelação e ensaio comportamental. Os resultados, avaliados por entrevistas e checklist, indicaram aumento nas práticas educativas parentais positivas, desenvolvimento de habilidades sociais educativas e desenvolvimento de estratégias saudáveis de enfrentamento a estressores externos nos participantes. Além da percepção positiva sobre mudanças no comportamento parental, os pais também avaliaram positivamente as mudanças dos filhos.

Unitermos: treinamento de pais; prática educativa; habilidades social.

\begin{abstract}
This paper describes an experience of parental training and its effects on positive educational practices, educational social skills and external stressors coping. Five mothers and two fathers attended to a group intervention, consisting of 20 weekly sessions, each one with 90 minutes of length. Behavioral techniques, such as modeling and role playing, were used. The results were evaluated by interviews and checklist and shown an increase of positive educational practices, educational social skills development and healthy coping strategies for external stressors. Besides the positive appraisal on parents'behaviors change, the parents also evaluated positively their children's changes.
\end{abstract}

Uniterms: parental training; educational practice; social skills.

A família proporciona o primeiro e mais importante contexto interpessoal para o desenvolvimento humano e, como resultado, as relações familiares têm uma profunda influência sobre a saúde mental das crianças. Ao atuarem como agentes de socialização dos filhos, os pais utilizam diversas estratégias e técnicas para orientar seus comportamentos, denominadas de práticas educativas parentais (Gomide, 2004).
As práticas educativas relativas ao estabelecimento de limites, à comunicação, ao ensino de responsabilidades e à expressão de afeto são apontadas como essenciais à promoção de auto-estima, autonomia e habilidades sociais nos filhos (Silva \& Marturano, 2002). Pais que estabelecem regras e zelam para que elas sejam cumpridas, que valorizam a aquisição de responsabilidades gradativas, que encorajam o diálogo e se dispõem

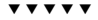

1 Universidade Católica de Goiás, Departamento de Psicologia. Av. Universitária, n. 1440, Setor Universitário, 74605-010, Goiânia, GO, Brasil. Correspondência para/Correspondence to: M.V. COELHO. E-mail:<mariliavelasco@hotmail.com>. 
a ouvir a criança e se mostram carinhosos têm mais chance de ensinar a seus filhos que sejam responsáveis, comunicativos e autoconfiantes em suas relações, prevenindo condutas impulsivas, agressivas ou excessivamente inibidas. Por outro lado, uma relação pouca afetuosa com os filhos, o uso de práticas disciplinares coercitivas ou inconsistentes e uma supervisão inadequada do comportamento dos filhos aumentam o risco das crianças desenvolverem problemas comportamentais e emocionais significativos (Gomide, 2003; Salvo, Silvares \&Toni, 2005).

Embora as relações familiares sejam importantes, os pais geralmente recebem pouca preparação, além da própria experiência como pais, produzindo-se a maior parte da aprendizagem durante a realização da tarefa por meio do ensaio e erro. O surgimento de problemas comportamentais e emocionais em crianças e adolescentes tem motivado o desenvolvimento de intervenções dirigidas aos pais, tais como o treinamento de pais (Olivares, Mendez \& Ros, 2005).

O trabalho com pais está fundamentado na premissa de que a falta de habilidades parentais é, pelo menos parcialmente, responsável pelo desenvolvimento ou manutenção de padrões de interação familiar perturbadores e, conseqüentemente, de problemas de comportamento nos filhos (Marinho, 2005).

Estudos anteriores mostram que a intervenção atingirá seu maior grau de eficácia se acontecer no meio familiar, quando esse for o contexto no qual se encontram as variáveis relevantes responsáveis pela manutenção do comportamento problema (Baraldi \& Silvares, 2003, Lohr, 2003; Olivares et al., 2005). Nesse caso, será necessário treinar pais ou qualquer outro adulto significativo do contexto familiar que possa contribuir, com seu comportamento, para manter o comportamento desadaptativo da criança ou do adolescente. Esses adultos, além de poderem intervir no momento preciso (por terem acesso imediato ao comportamento problema), geralmente controlam reforçadores muito poderosos e significativos para a criança e para o adolescente, tais como atenção e afeto. Por essas razões, os pais são, usualmente, o principal agente de mudança no processo terapêutico de seus filhos, atuando como mediadores entre a orientação profissional e a implementação de contingências favoráveis à mudança da criança em seu ambiente natural (Mestre \& Corassa,

334 2002; Silvares, 1995).
A mudança que se deseja produzir nos filhos irá requerer mudanças no modo de comunicação dos pais com seus filhos, tais como em suas habilidades de expressar sentimentos positivos e negativos, ouvir com empatia, fazer e responder a perguntas, admitir erro e pedir desculpas, dar e pedir feedback e demonstrar aceitação ou reprovação do comportamento dos filhos de maneira assertiva (Del Prette \& Del Prette, no prelo). Essas são consideradas habilidades sociais educativas por serem direcionadas à promoção de desenvolvimento e aprendizagem (Del Prette \& Del Prette, 2001). A criança cujos pais apresentam um repertório mais desenvolvido de habilidades sociais educativas tem mais chances de desenvolver autonomia, competência social, auto-eficácia e melhor desempenho acadêmico (Marturano \& Loureiro, 2003; Silva \& Marturano, 2002).

A constatação de que práticas educativas parentais e habilidades sociais educativas atuam como fatores de proteção ao desenvolvimento socioemocional (Gomide, 2003) tem estimulado a implementação de programas de intervenção voltados para o desenvolvimento dessas competências parentais.

Marinho (2005) promoveu um programa de intervenção comportamental em grupo para pais que apresentavam queixas com relação aos comportamentos de seus filhos de idade entre três e onze anos. A intervenção constava de dez sessões, uma por semana, com duração de noventa minutos. Teve como objetivo ensinar os pais a observar e descrever o comportamento da criança e a ser agentes mais eficazes de reforço, aumentando a freqüência, a variedade e a extensão de reforços sociais para as crianças e reduzindo a freqüência de comportamentos verbais competidores, como críticas, ordens e questionamentos. Os resultados demonstraram que o programa produziu mudanças comportamentais positivas na maioria das famílias submetidas à intervenção.

Baraldi e Silvares (2003) realizaram um programa de atendimento em grupo de pais e crianças com queixas de agressividade. O grupo era composto por 16 crianças na faixa etária dos seis aos dez anos e suas mães. As mães foram atendidas em um grupo de orientação, com duração de cinqüenta minutos, uma vez por semana. O programa foi estruturado para ter 15 sessões, porém foi considerado necessário prolongar o atendimento por mais tempo, sendo adicionadas nove 
sessões devido a três fatores: as mães relatavam que seus filhos ainda não haviam melhorado, as crianças não mostraram diminuição de integração negativa e foi detectado através de uma avaliação sociométrica que as crianças eram vistas negativamente por seus pares na escola.

As mães recebiam orientações a respeito de dar instruções de forma clara e eficiente para seus filhos, como também foi ensinado como lidar melhor com os filhos através do ensino de princípios básicos do comportamento como reforço diferencial e extinção. Os resultados demonstraram que tanto os comportamentos positivos das mães quanto das crianças aumentaram no decorrer da intervenção, e que os comportamentos negativos de ambos diminuíram, melhorando assim suas relações.

Um estudo destinado a avaliar os efeitos de uma intervenção para o desenvolvimento de habilidades sociais educativas em pais de crianças com problemas de comportamento foi feito por Pinheiro, Haase, Del Prette, Amarente \& Del Prette (2006). Participaram desse programa 32 famílias, sendo a maioria de mães. A intervenção teve duração de 11 semanas com encontros semanais de aproximadamente uma hora e trinta minutos, e consistiu na apresentação de princípios da análise do comportamento e modelos de habilidades sociais educativas para pais. As avaliações pré e pósintervenção foram feitas por meio de questionário de auto-relato e entrevistas. Os resultados mostraram redução significativa na freqüência e severidade de comportamentos inoportunos e/ou indisciplinados, conforme avaliados pelos pais.

A revisão da literatura mostra que os estudos que investigam o efeito de intervenções para pais têm enfocado o desenvolvimento de habilidades para modificação de padrões coercitivos ou negligentes na interação com a criança. Porém alguns autores (Silva \& Marturano, 2002) salientam que é necessário intervir sobre outros aspectos do repertório dos pais, como o enfrentamento a estressores não relativos ao papel parental, como dificuldades conjugais, dificuldades financeiras, experiências negativas de vida e falta de suporte social. Um modelo de intervenção mais amplo se justificaria porque o estresse dos pais, decorrente de um repertório inadequado ou insuficiente de enfrentamento, pode contribuir para o uso de práticas educativas coercitivas ou negligentes com a criança (Silva \& Marturano, 2002).

Em conformidade com essa argumentação, o presente artigo descreve uma experiência de intervenção grupal para pais voltada para o desenvolvimento de múltiplas habilidades, além das habilidades típicas do papel parental. Trata-se de uma experiência de intervenção multimodal focada no desenvolvimento de práticas educativas parentais saudáveis, habilidades sociais educativas e de manejo de estressores externos. Especificamente, o estudo buscou avaliar os efeitos desse programa estruturado de treinamento de pais em grupo sobre o desenvolvimento de práticas educativas parentais positivas, habilidades sociais educativas e estratégias adequadas de enfrentamento a estressores externos.

\section{Método}

\section{Participantes}

Participaram do programa sete pais/mães na faixa etária entre 31 e 50 anos, e escolaridade entre o ensino fundamental e ensino médio. A renda individual apresentada pelos pais variava aproximadamente de um salário mínimo a três salários. As características demográficas e queixas dos pais relativas aos filhos estão descritas na Tabela 1. Como a proposta do presente estudo implicava em um trabalho conjugado envolvendo pais e crianças, foi desenvolvido paralelamente ao programa de pais um programa de treinamento em habilidades sociais para os filhos, implementado em grupo, com base no referencial cognitivo-comportamental, composto por 20 sessões e periodicidade semanal (Gonçalves, 2005).

Os participantes foram recrutados a partir das fichas de triagem de seus filhos disponibilizadas no Centro de Estudos, Pesquisa e Prática Psicológica (CEPSI), a clínica-escola de Psicologia da Universidade Católica de Goiás. Os pais foram convidados por telefone a participar de um programa de orientação a pais, e seus filhos para participarem do programa de habilidades sociais. Segundo o critério de inclusão, tanto os pais quanto os filhos deveriam participar dos programas sugeridos. 
Tabela 1. Características dos participantes do Programa de Treinamento em Práticas Educativas Parentais.

\begin{tabular}{|c|c|c|c|c|c|c|}
\hline Participantes & sexo & Idade & Profissão & Escolaridade & $\begin{array}{l}\text { Renda individual } \\
\text { (salários mínimos) }\end{array}$ & Queixa em relação aos filhos \\
\hline P1 & F & 35 & Doméstica & Ensino fundamental & $>1$ & $\begin{array}{l}\text { Dificuldade de aprendizagem, } \\
\text { timidez excessiva }\end{array}$ \\
\hline P2 & $\mathrm{F}$ & 31 & Faxineira & Ensino médio & $>1$ & $\begin{array}{l}\text { Agressividade, individualismo } \\
\text { Dificuldade em manter interação } \\
\text { com outras crianças }\end{array}$ \\
\hline P3 & F & 39 & $\begin{array}{l}\text { Operadora } \\
\text { de máquina }\end{array}$ & Ensino médio incompleto & $>1$ & $\begin{array}{l}\text { Dificuldade de aprendizado, não } \\
\text { respeita adultos, não tem limites }\end{array}$ \\
\hline P4 & M & 41 & Marceneiro & Ensino fundamental & $>2$ & Inquieto, não se alimenta. \\
\hline P5 & F & 38 & Costureira & $\begin{array}{l}\text { Ensino fundamental } \\
\text { Ensino médio }\end{array}$ & $>1$ & $\begin{array}{l}\text { Dificuldade de concentração e } \\
\text { atenção }\end{array}$ \\
\hline P6 & M & 50 & Gerente & Ensino médio & & atenção \\
\hline \multirow[t]{2}{*}{ P7 } & $\mathrm{F}$ & 38 & Auxiliar de escritório & Ensino médio & $>3$ & Não tem limites, agressividade \\
\hline & & & & & $>2$ & $\begin{array}{l}\text { Birras excessivas em casa, } \\
\text { indisciplinado }\end{array}$ \\
\hline
\end{tabular}

F: feminino; M: masculino.

\section{Instrumentos}

Foi utilizado um Roteiro de Entrevista NãoEstruturada para Avaliação Inicial, que teve como objetivo recolher dados sobre a relação entre pais e filhos, de forma a realizar-se uma análise funcional inicial de cada caso. A entrevista era composta por duas questões abertas, uma referente às queixas apresentadas pelos pais em relação a seus filhos, e a segunda sobre a maneira como eles lidavam com tais problemas.

Outro instrumento utilizado foi a Lista de Verificação Comportamental - Child Behavior Checklist (CBCL) (Achenbach, 1991) para crianças e adolescentes de quatro a dezoito anos. É um inventário de avaliação de comportamento utilizado para avaliar competência social e problemas comportamentais, respondido pelos pais.

Neste trabalho foi aplicada somente a primeira parte desse instrumento, que corresponde à avaliação da competência social, agrupada em três escalas: atividade, sociabilidade e escolaridade, fornecendo a soma dos escores brutos das três escalas o escore final da competência social. Os resultados ponderados no CBCL permitem classificar as crianças em: não-clínica, limítrofe e clínica (Bordin, Mari \& Caiero, 1995). Para a escala de competência social, a categoria clínica corresponde a escores abaixo de 30, a limítrofe entre 30

336 e 33 e a categoria não-clínica acima de 33.
Foi utilizado também um Roteiro de Entrevista Não-Estruturada para Avaliação Final, contendo duas perguntas abertas. A primeira buscava avaliar as práticas educativas parentais, as habilidades sociais educativas e o enfrentamento a estressores externos (compreende estressores além da relação pais-filhos, tais como os relativos ao casamento, família de origem, estudo e autocuidado), que os pais teriam desenvolvido durante a intervenção. A segunda compreendia as mudanças apresentadas pelos filhos após sua participação no programa, segundo a percepção dos pais.

\section{Materiais}

Os atendimentos aos grupos foram realizados em consultórios do CEPSI, com mesas, cadeiras e almofadas. Os materiais utilizados foram divididos em quatro grupos; 1) materiais de papelaria, que incluía papel sulfite, canetas, lápis, entre outros; 2) jogos educativos; 3) jogos lúdicos: brinquedos e materiais para as dinâmicas de grupo e 4) material de filmagem: filmadora, fitas VHS, e Termo de Consentimento Livre e Esclarecido.

\section{Procedimentos}

O programa teve formato grupal, psicoeducativo, com o objetivo de desenvolver práticas 
educativas parentais saudáveis e habilidades comunicativas e de enfrentamento ao estresse. Os participantes foram divididos em dois grupos: o grupo vespertino, composto por três mães, e o grupo noturno, por dois pais e duas mães. Ambos os grupos tiveram 20 sessões de 90 minutos, com periodicidade semanal. Embora cada sessão de atendimento abordasse um tema específico o qual estava encadeado com a temática dos encontros seguintes, era realizada após cada sessão e durante as supervisões uma análise funcional do processo. Esse procedimento facilitou o planejamento das sessões seguinte, ajustando a implementação do programa às demandas do grupo. Duas estagiárias de graduação em psicologia atuaram como facilitadoras do grupo.

O processo de intervenção ocorreu em quatro fases. A fase inicial foi realizada em quatro sessões e consistiu da apresentação dos membros do grupo, realização do contrato terapêutico e avaliação inicial. A fase intermediária I, realizada em sete sessões, tratou de princípios de análise do comportamento, práticas educativas parentais (Gomide, 2004) e habilidades sociais educativas (Del Prette \& Del Prette, no prelo; Silva \& Marturano, 2002). A fase intermediária II, desenvolvida em sete sessões, abordou enfrentamento a estressores externos (Marinho, 2005), responsividade na interação entre pais e filhos e convívio social e conjugal (Silva \& Marturano, 2002). E, por fim, a fase final foi realizada em duas sessões, usadas para avaliação final. A temática de cada sessão e as técnicas utilizadas estão descritas na Tabela 2.

A análise dos dados obtidos através das entrevistas foi feita via análise de conteúdo. E os dados coletados através do CBCL foram analisados por meio de um software específico.

Tabela 2. Descrição das sessões do grupo de pais.

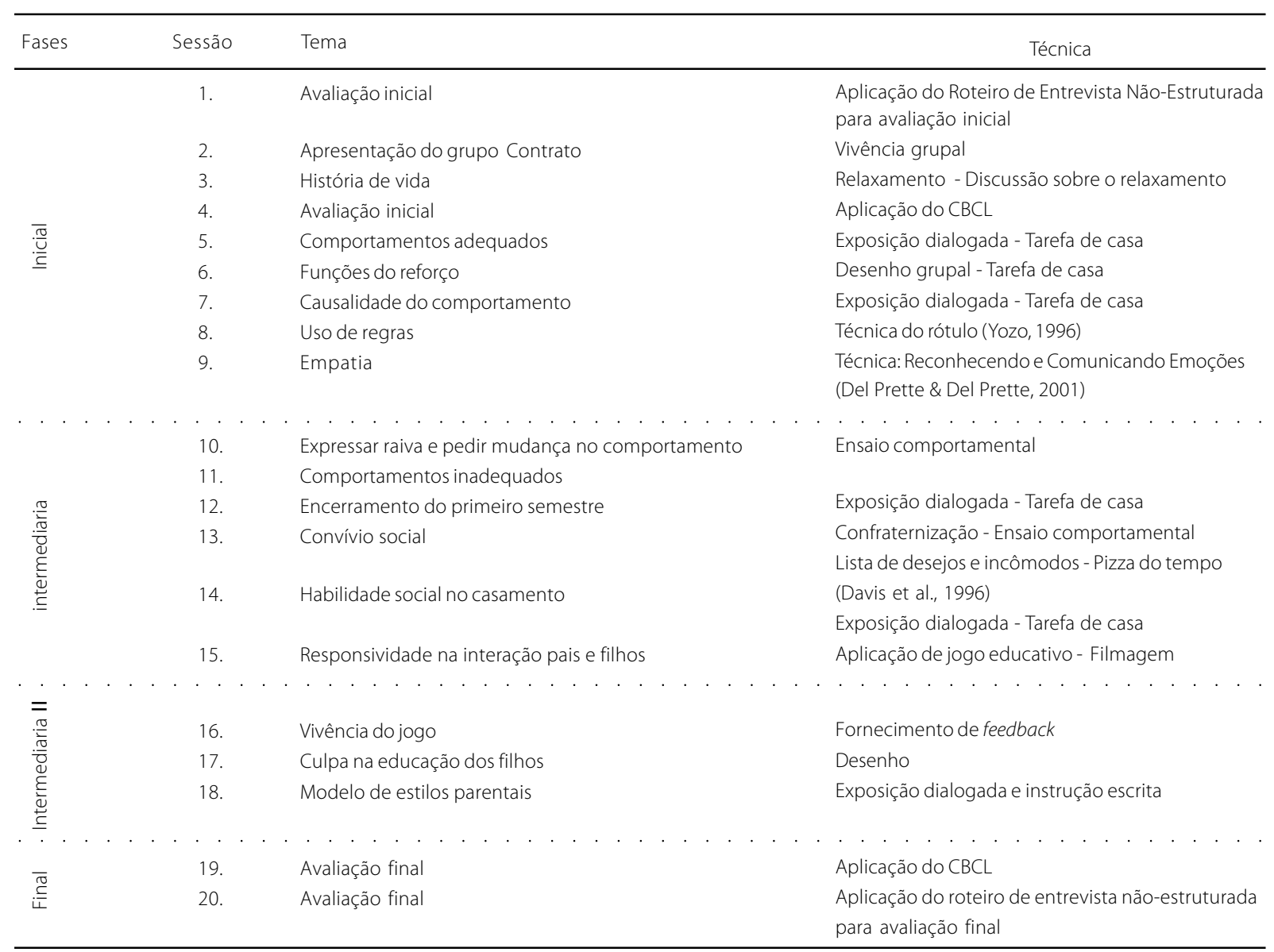




\section{Resultados}

Os dados coletados nos dois grupos foram analisados conjuntamente, uma vez que não foi observado desempenho diferenciado entre os grupos vespertino e noturno. Os resultados foram analisados a partir do relato dos participantes através das entrevistas, da observação clínica e dos escores obtidos pela aplicação do CBCL. A análise da entrevista e da observação clínica foi dividida em duas categorias. A primeira considerou as melhoras apresentadas pelos participantes (pais e mães). Tais melhoras foram categorizadas em três subcategorias: práticas educativas parentais, habilidades sociais educativas e enfrentamento a estressores externos. E a segunda categoria consistiu nas melhoras apresentadas pelos filhos, categorizadas também em três subcategorias: habilidades sociais, desempenho acadêmico e autocuidado. A análise do CBCL foi categorizada pelos escores obtidos em clínica, limítrofe e não-clínica.

\section{Mudanças no comportamento dos participantes}

- Práticas educativas parentais: antes da intervenção os participantes utilizavam práticas educativas predominantemente negativas e após o programa o uso dessas práticas foi reduzido. As práticas negativas (a classificação proposta por Gomide, 2004, foi usada para essa categorização) são:

a) punição física: caracterizada quando os pais batem com raiva em seus filhos, não tendo caráter educativo, sendo simplesmente punitivo, exemplo: "antes eu batia por qualquer coisa, xingava e gritava coisas horríveis para meu filho, agora eu converso com ele num tom baixo e não bato mais, pois bater não adianta nada";

b) supervisão estressante: caracterizada pela exagerada vigilância ou fiscalização dos pais para com seus filhos, exemplo: "estava controlando o meu filho em tudo o que ele fazia, depois do grupo eu tenho confiança nele para deixá-lo fazer as coisas sem eu vigiar";

c) negligência: caracteriza a falta de interação, de vínculo afetivo positivo e de demonstração de 338 interesse, exemplo: "não tinha um pingo de paciência com minha filha, não queria saber nada sobre ela, nunca dava beijos e abraços, depois do que eu aprendi aqui eu tenho demonstrado carinho e dito coisa bonitas para ela";

d) humor instável: quando se aplica uma punição em função do humor; exemplo:"quando estava brava com coisas do emprego chegava em casa e descontava nos meus filhos, agora eu não tenho mais transferido os problemas de lá de fora para dentro da minha casa".

Após a intervenção os participantes apresentaram um aumento nas práticas educativas positivas, dando continuidade à classificação proposta por Gomide (2004):

e) uso de regras: coerentes e possíveis de serem cumpridas: exemplificado pela fala:"agora consigo impor uma regra e permanecer com ela, sem que eles me desobedeçam";

f) monitoria positiva: caracterizada pela demonstração de que os filhos são amados e importantes, exemplo: "quando eu converso com o meu filho eu falo e escuto ele, estou respeitando mais, sempre estou perguntando o seu ponto de vista";

g) modelo moral: corresponde a valores morais de justiça, respeito ao direito do outro, e se colocar no lugar do outro, por exemplo: "depois deste programa tenho conversado com meus filhos sobre a importância de respeitar os irmãos e de dividir os brinquedos com eles".

- Habilidades sociais educativas: os participantes relataram ter desenvolvido durante a intervenção algumas habilidades sociais no exercício do papel parental, dentre elas:

a) cumprir promessas, que serve de modelo aos filhos; exemplo:"havia muito tempo que prometi a ele de arrumar sua bicicleta, esses dias levei a bicicleta para o conserto";

b) expressar sentimentos, o que ajuda os filhos a discriminar comportamentos positivos e negativos; exemplo:"estou mais carinhosa com minha filha, tenho falado que a amo";

c) pedir desculpas, admitindo o próprio erro e servindo de modelo; exemplo:"esses dias gritei com ele e pedi imediatamente desculpas"; 
d) escuta empática, que permite escutar o outro e colocar-se em seu lugar; exemplo: "não mando mais eles calarem a boca na hora da discussão, agora peço pra eles contarem o que aconteceu".

- Enfrentamento aestressores externos:foiverificado que após a intervenção os participantes desenvolveram estratégias de enfrentamento em contextos diferentes daquele que envolve o relacionamento com os filhos. Dentre os estressores externos estão:

a) relacionamento conjugal, indicando cumplicidade entre o casal; exemplo: "eu e o meu marido nos aproximamos mais e estamos conversando sobre a educação das crianças, que antes era só de minha responsabilidade";

b) estudos, indicação de busca de crescimento profissional e pessoal; exemplo: "voltei a estudar este ano e estou estudando para prestar concursos públicos";

c) família de origem, corresponde à maneira de se relacionar atualmente com as pessoas da infância; exemplo: "agora sei lidar melhor com minha mãe, não me sinto mais tão ofendida com as agressões dela";

d) enfrentamento focado no problema, que inclui o uso de estratégias saudáveis para lidar com problemas pessoais; exemplo: "estou tentando ser independente e pretendo voltar para minha casa e não ficar morando na casa dos outros" e "o programa me ajudou na resolução de alguns problemas, pois agora procuro alternativas antes de tomar as decisões".

\section{Mudanças observadas no comportamento dos filhos}

As mudanças relatadas pelos pais acerca dos comportamentos dos filhos foram agrupadas em três categorias descritas a seguir:

- Desempenho acadêmico: todos os participantes relataram que as notas dos filhos na escola melhoraram, que eles estavam fazendo as tarefas escolares com mais facilidade e copiavam a matéria da lousa, e que antes deixavam os cadernos em branco. Três participantes observaram que seus filhos estavam mais interessados em leitura e escrevendo mais corretamente.

- Habilidades sociais: referem-se às diferentes classes de comportamentos socialmente adequados. As melhoras observadas neste item foram divididas em três categorias: relacionamento com os pais, com os irmãos e com os colegas. Na categoria relacionamento com os pais, todos os participantes relataram que o diálogo se tornou melhor, que seus filhos estavam mais obedientes, carinhosos, tranqüilos e menos agressivos com eles. Na categoria relacionamento com irmãos, a maioria dos participantes mencionou que seus filhos estavam brigando menos com os outros irmãos e brincando mais com eles. Na categoria relacionamento com os colegas, poucos participantes observaram melhoras nesse item, aqueles que perceberam mudanças mencionaram que os filhos estavam pedindo para brincar mais com os colegas e brigando menos com eles.

- Autonomia: diz respeito à realização de atividades com um grau progressivo de responsabilidade e independência dos pais. A maioria dos pais relatou aumento nas atividades de lazer de seus filhos, que estavam brincando mais nas casas de parentes e colegas. Dois participantes (o casal) perceberam que o filho estava se alimentando melhor, e não requeria mais ajuda na hora das refeições, que já se arrumava sozinho para ir a escola e estava demonstrando organização em outras atividades desempenhadas.

\section{CBCL}

Antes da intervenção duas crianças obtiveram escore clínico e após o programa houve um aumento significativo no escore da competência social, mudando para a categoria não-clínica. Duas outras crianças no início obtiveram escores da categoria não-clínica e posteriormente aumentaram os escores, mas não mudaram de categoria. E uma criança antes da intervenção obteve escore da categoria limítrofe, e após o programa mudou para a categoria não-clínica.

\section{Discussão}

Os resultados da intervenção mostraram que os objetivos do programa foram alcançados. A análise dos resultados permite concluir que as participantes apresentaram melhoras no sentido esperado da intervenção, tendo em vista que diminuíram as práticas educativas parentais negativas e aumentaram consideravelmente as práticas positivas. No que se refere 
às habilidades sociais educativas foi verificado que os participantes desenvolveram algumas dessas habilidades no exercício do papel parental. Com relação ao enfrentamento a estressores externos, os pais-mães relataram o desenvolvimento de habilidades para lidar com outros eventos estressores além da relação paisfilhos ao longo da intervenção.

Além da percepção positiva sobre mudanças no comportamento parental, os pais também avaliaram positivamente as mudanças dos filhos, relatando melhoras nas atividades acadêmicas, no desenvolvimento de habilidades sociais e no desenvolvimento de cuidados em prol da própria saúde. Dessa forma, observa-se consistência entre a literatura e os resultados obtidos: o treinamento de pais altera positivamente a qualidade das relações entre pais e filhos e reduz problemas de comportamento na criança (Baraldi \& Silvares, 2003; Olivares et al., 2005; Salvo et al., 2005; Pinheiro et al., 2006).

Dentre os resultados nas melhoras apresentadas pelos filhos, na categoria relacionamento com os colegas, foi constatado que poucos pais-mães perceberam melhoras nesse aspecto, o que pode ser justificado, pois a maioria dos participantes não tinha acesso ao comportamento dos filhos em interação com outras crianças (colegas de escola, vizinhos), pelo fato de trabalharem durante o dia todo e as crianças ficarem sob cuidados de outras pessoas ou sozinhas. Dessa forma, os pais não podiam acompanhar os filhos em interação com colegas.

De acordo com a análise do CBCL e do relato dos pais, foi percebido que todas as crianças após a intervenção tiveram melhoras significativas no desempenho acadêmico; esse fato pode ser atribuído aos recursos do ambiente familiar que podem afetar diretamente o desempenho e o ajustamento escolar, e que foram favorecidos pela intervenção. Recursos como o clima emocional familiar positivo, a instrução de regras e rotinas no lar, o suporte à autonomia, o envolvimento dos pais com a escolaridade dos filhos e a oferta de atividades sociais e culturais enriquecedoras durante os anos da escola favorecem o bom desempenho escolar, sociabilidade na sala de aula, auto-regulação e percepção de controle por parte da criança (Marturano

340 \&Loureiro, 2003).
Todos os instrumentos utilizados nessa intervenção foram respondidos apenas pelos pais. Cabe ressaltar que são escassos os instrumentos sobre o assunto a serem respondidos por outros informantes, como os filhos, disponíveis no Brasil. Uma exceção é o Inventário de Estilos Parentais (Gomide, 2003), que requer habilidade de leitura e escrita para seu preenchimento. A amostra deste estudo, porém, não possuía tais habilidades. Sugere-se que futuras intervenções utilizem instrumentos a serem respondidos pelos filhos ou parentes acerca da maneira utilizada pelos pais nos cuidados com seus filhos.

Os relatos dos pais sugeriram que houve generalização de seus comportamentos e de seus filhos em outros ambientes, além do consultório. Entretanto todas intervenções e avaliações foram realizadas em ambiente de clínica-escola. Assim, se faz necessário que o programa estenda a observação para outros contextos. Programas futuros poderiam utilizar medidas observacionais da interação pais e filhos, conduzida no ambiente natural, para que a generalização possa ser constatada por outras vias, além da verbalização dos pais nas entrevistas.

Outra sugestão para novos estudos é que seja conduzida avaliação de processo da intervenção para registrar mudanças em metas intermediárias ao longo da intervenção ou indicadores de satisfação do paciente. Análises desse tipo de avaliação poderiam auxiliar na interpretação dos resultados finais do programa. Uma última sugestão é que estudos futuros verifiquem em que extensão a classe social afeta as práticas educativas parentais, bem como as diferenças na adesão ao tratamento entre pais e mães. É provável que o estudo dessas variáveis psicossociais possa trazer importantes contribuições para o planejamento de programas futuros, adequando-os às demandas do contexto e da população-alvo.

Em conclusão, os resultados demonstraram que o programa foi avaliado como benéfico para a melhoria das relações interpessoais, incluindo a relação com os filhos, com o cônjuge e com a família de origem, e para o aumento no repertório de solução de problemas e autocuidados, tanto nos pais quanto nos filhos. A variedade de resultados positivos obtidos com o programa multimodal, focado no desenvolvimento de práticas educativas parentais saudáveis, habilidades 
socioeducativas e habilidades de enfrentamento a estressores externos, justifica sua replicação para outros contextos, como o contexto escolar.

A implantação de programas dessa natureza em escolas poderá atingir um número maior de pais e educadores, e capacitá-los para atuarem como uma rede de apoio social promotora de saúde em crianças e adolescentes (Marturano \& Loureiro, 2003). Replicações poderiam também comparar esse tipo de tratamento com tratamentos alternativos e grupos-controle.

Os ganhos advindos com novos estudos na área poderão fortalecer a tecnologia empregada em serviços preventivos ou de tratamento em saúde mental, o que poderá interessar não somente a clínicos e pesquisadores, mas também a gestores em políticas públicas de educação, saúde e assistência social à infância e adolescência.

\section{Referências}

Achenbach,T.M. (1991). Manual for the child behavior checklist/ 4-18 and 1991 profile. Burlington: University of Vermont.

Baraldi, D. M., \& Silvares, E. F. M. (2003). Treino de habilidades sociais em grupo com crianças agressivas, associado à orientação dos pais: analise empírica de uma proposta de atendimento. In A. Del Prette \& Z. A. P. Del Prette (Orgs.), Habilidades sociais, desenvolvimento e aprendizagem (pp.235-258). Campinas: Alínea.

Bordin, I. A. S., Mari, J. J., \& Caiero, M. F. (1995). Validação da versão brasileira do Child Behavior Checklist (CBCL) [Inventario de comportamentos da infância e adolescência: dados preliminares: Revista ABP-APAL, 17 (2), 55-66.

Davis, M., Eshelman, E. R., \& McKay, M. (1996). Manual de relaxamento e redução do stress. São Paulo: Summus .

Del Prette, A., \& Del Prette, Z. (2001). Psicologia das relações interpessoais: vivências para o trabalho em grupo. Petrópolis: Vozes.

Del Prette, A., \& Del Prette, Z. A. P. (no prelo). Adolescência e fatores de risco: a importância das habilidades sociais educativas. In F. J. Penna \& V. G. Haase (Orgs.)., Aspectos psicossociais da saúde na infância e adolescência. Belo Horizonte: Coopmed.
Gomide, P. I. C. (2003). Estilos parentais e comportamento anti-social. In A. Del Prette \& Z. A. P. Del Prette (Orgs.), Habilidades sociais, desenvolvimento e aprendizagem (pp.2160). Campinas: Alínea.

Gomide, P. I. C. (2004). Pais presentes, pais ausentes. Petrópolis: Vozes.

Gonçalves, E. S. (2005). Agressividade infantil à luz das habilidades sociais. Artigo de Graduação não-publicado, Universidade Católica de Goiás, Goiânia.

Lohr, S. S. (2003). Estimulando o desenvolvimento de habilidades sociais em idade escolar. In A. Del Prette \& Z. A. P. Del Prette (Orgs.), Habilidades sociais, desenvolvimento e aprendizagem (pp. 293-310). Campinas: Alínea.

Marinho, M. L. (2005). Um programa estruturado para o treinamento dos pais. In V. E. Caballo \& M. A. Simon (Orgs.), Manual de psicologia clínica infantile do adolescente: transtornos específicos (pp.417-443). São Paulo: Santos.

Marturano, E. M., \& Loureiro, S. R. (2003). O desenvolvimento socioemocional e as queixas escolares. In A. Del Prette \& Z. A. P. Del Prette (Orgs.), Habilidades sociais, desenvolvimento e aprendizagem (pp.259-291). Campinas: Alínea.

Mestre, M., \& Corassa, N. (2002). Mediadores no sucesso da psicoterapia comportamental. In H. J. Guilhardi, M. B. Madi, P. P. Queiroz \& M. C. Scoz (Orgs.), Sobre comportamento e cognição (Vol. 10, pp.221-240). Santo André: ESETec Editores Associados.

Olivares, J., Mendes, F. X., \& Ros, M. C. (2005). O treinamento de pais em contexto clínicos e da saúde. In V. E. Caballo \& M. A. Simon (Orgs.), Manual de psicologia clínica infantile do adolescente: transtornos específicos (pp.365-385). São Paulo: Santos.

Pinheiro, M. I. S., Haase, V. G., Del Prette, A., Amarente, C. L. D., \& Del Prette, Z. A. P. (2006). Treinamento de habilidades sociais educativas para pais de crianças com problemas de comportamento. Psicologia: Reflexão e Crítica, 19 (3), 407414.

Silva, A., \& Marturano, E. (2002). Práticas educativas e problemas de comportamento: uma análise a luz das habilidades sociais. Estudos de Psicologia, 7 (2), 227-235.

Silvares, E. F. M. (1995). Intervenção clínica e comportamental com crianças. In B. Range (Org.), Psicoterapia comportamental e cognitiva: pesquisa, prática, aplicações e problemas (pp.133-141). Campinas: Editorial Psy.

Yozo, R. Y. K. (1996). 100 jogos para grupo: uma abordagem psicodramática para empresas, escolas e clínicas. São Paulo: Agora.

Recebido em: 11/4/2006

Versão final reapresentada em: 19/9/2006

Aprovação em: 16/11/2006 
